\title{
Evaluating uncertainty for the standardization of single cell/stack power generation performance tests for SOFC
}

\author{
- Standardizing test methods and ensuring reliability of test results for \\ the commercialization of SOFC -
}

\author{
Akihiko Momma*, Kiyonami Takano, Yohei TAnaKa and Tohru Kato
}

[Translation from Synthesiology, Vol.5, No.4, p.243-252 (2012)]

\begin{abstract}
SOFC (solid oxide fuel cell) is a very promising technology that achieves high power generation efficiency, while being very nearly usable. It is high time we considered enhancing commercialization and dissemination of SOFC by setting a standard for the evaluation method of SOFC cell/stack performance. In setting the standard, it is neither appropriate to describe the specific content or form of the test object, nor appropriate to unify the test conditions, because each type of SOFC has been developed for a different application owing to the diversity of SOFC. On the other hand, uncertainty evaluation of the test results has been introduced to ensure reliability. In setting a standard for the SOFC performance test, it is necessary that the method for uncertainty evaluation be specifically described in the text, because the performance of SOFC depends on many parameters. This report describes the approaches we have taken in order to set the international standard of the SOFC test method and to evaluate the uncertainty of the test results.
\end{abstract}

Keywords : Solid oxide fuel cell, SOFC, uncertainty, performance evaluation, standardization

\section{Introduction}

Since the 1970s, Solid Oxide Fuel Cell (SOFC) has been a major focus of research and development in Japan. As a result of government-funded and other projects, the technology is now fast approaching commercialization. A number of manufacturers outside Japan are believed to already have the capability to provide a continuous supply of SOFC systems ranging from $1 \mathrm{~kW}$ to a few hundred $\mathrm{kW}$. In Japan, $700 \mathrm{~W}$-class SOFCs were introduced on the market last year as the core technology of the ENE-FARM system.

While SOFC systems are thus already available for practical and commercial purposes from some manufacturers, the technology has not yet attained the level where cell/stack (i.e. single cells in a stack) products backed by sufficiently reliable data are widely traded. These products are still in the development stage, with issues relating to long-term durability and manufacturing cost unresolved in many cases.

In order to address these issues, Europe took initiatives to harmonize and standardize testing conditions through such projects as the Fuel Cell TEsting and STandardisation NETwork (FCTESTNET) and its successor, the Fuel Cell Systems TEsting, Safety and Quality Assurance (FCTESQA), ${ }^{[1]}$ thereby accelerating the research and development efforts. The main aim of the standardization work was to facilitate cross-border comparisons of the results of round robin tests by harmonizing the test procedures and conditions. For this reason the test conditions were very specifically described, and the flat-plate type was the only type of SOFC single cell/stack covered extensively, since it was the focus of development in Europe.

In Japan, while there were ongoing SOFC-related research and development projects conducted by the New Energy and Industrial Technology Development Organization (NEDO) and other organizations, the efforts to standardize testing methods were lagging behind those of Europe.

In addition, research and development on SOFCs in Japan took a wide variety of approaches. The goal was to ensure reliability in all applications by securing mechanical strength and reducing the rate of degradation under many different service conditions conceivable at high temperature, the operating environment associated with SOFC. This has led to the development of many types of SOFCs differing in geometry and cell size. Since different operating conditions are appropriate for different types of SOFC, establishing test conditions by simply integrating these different operating conditions would disregard the fact that each SOFC was designed with a certain type of service condition in mind. Comparisons of SOFCs based on such test conditions are not appropriate and defeat the purpose of making such comparisons in the first place.

Given such circumstances, it was necessary that Japan take a leading role in the development of international standards on

Energy Technology Research Institute, AIST Tsukuba Central 2, 1-1-1 Umezono, Tsukuba 305-8568, Japan * E-mail: mo.momma@aist.go.jp

Original manuscript received April 3, 2012, Revisions received May 2, 2012, Accepted May 11, 2012 
the testing methods for SOFCs in commercial transactions. Japan's leadership would allow many types of SOFCs designed for different service conditions to be tested fairly; data obtained from the test results would be used as the basis for commercial transactions of SOFCs, making it possible to select SOFCs appropriate for different applications and thereby accelerating the development and widespread application of SOFCs.

Our group has been leading the research efforts relating to the standardization initiatives aimed at the broad-based acceptance and development of SOFCs. Our projects include the preparation of a Japanese Industrial Standard Technical Specifications (JIS TS $)^{[2]}$ on efficiency measurement methods based on such studies as: the development of the flow rate standards of hydrogen and city gas ${ }^{[3]}$ — both of which are potential fuels for fuel cells - and the development of highprecision efficiency measuring methods for SOFC systems (figure 1). ${ }^{[4]}$ In addition, we have been consolidating the SOFC measurement technology by conducting measurements on various types of single cells as well as cell stacks and systems. $^{[5]}$

Based on these technologies and experiences and in light of the future prospects of SOFC, our group was commissioned in 2007 by the Ministry of Economy, Trade and Industry (METI) to begin work on the standardization and harmonization of the single cell/stack testing methods for SOFC. Standardized testing methods were considered vital in order to facilitate the commercial transactions of SOFCs and accelerate the widespread use of SOFCs, which were believed to be close to commercialization.

In preparing an international standard for SOFC performance tests, it is necessary to address the accuracy of data to ensure the reliability of measurements. Standards published by the International Electrotechnical Commission (IEC) and other international standards propose the inclusion of uncertainty - a concept traceable to international and national standards - as a benchmark for the quantitative evaluation of the reliability of measurement results. Measurement results with uncertainty data would permit cross-border comparisons of test results, an essential part of any relevant international standard.

Against this background, we have taken active steps to introduce the concept of uncertainty into the evaluation of SOFC performance. As part of the JIS TS work and a 2007 project on efficiency measurements using an actual $10-\mathrm{kW}$ SOFC system, we conducted uncertainty analyses of measured input and output values and included uncertainty data in our evaluation of the measured efficiency. ${ }^{[6]}$

This paper describes the three-year project commissioned by METI in 2007 to develop an international standard for the cell/stack performance testing of SOFC, and our group's work on uncertainty evaluation as part of this project.

\section{Study objectives and a scenario for realizing the objectives}

As mentioned above, the objectives of this research were to propose an international standard for SOFC testing methods and to incorporate into the standard the equations and methods for evaluating uncertainty that are practical for the current level of technology.

The first step was to form a committee for discussing and reviewing the draft standard. To do so we first conducted an inquiry, which included a questionnaire survey, with

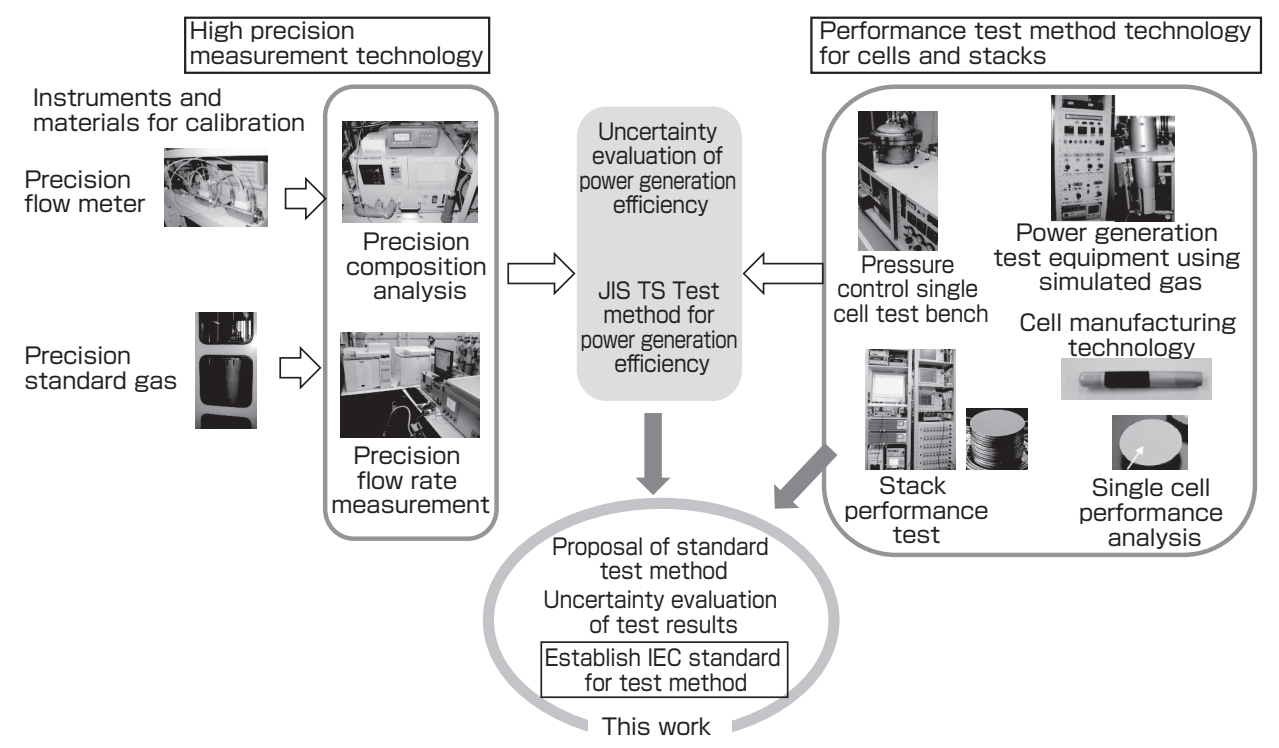

Fig. 1 The integration of and relationship between the technologies used for this study 
SOFC manufacturers to ascertain their views concerning the testing methods they used and the standardization of such testing methods. It was important that the composition of the committee membership be equally distributed among the manufacturers, users, and neutral parties, so that discussions would reflect a balanced perspective. Regrettably, however, because SOFC was still in the development phase and the number of its actual users was limited, the committee debates tended to favor the manufacturers' views.

The second step was to establish the scope of measurements in the proposed standard. As described above, SOFCs came in a wide range of shapes and sizes; it was therefore neither easy nor realistic to set standards on all details of the components and their physical states and testing conditions during the tests. This was one of the most troubling issues that we had to address as we prepared the standard. In the end we selected the following approach:

(1) Define the scope of the tests as "cell/stack assembly" to make clear that the standard covers both cells and stacks;

(2) Treat the cell/stack assembly as a "black box" so that it can be applicable to any type of SOFC;

(3) Define the interface between the measurement instrument system and the cell/stack assembly, and describe the necessary interfaces and the measurement methods of input and output values based on such interfaces.

In sum, this approach is based on the view that it is not necessarily advisable to set standards for all details of the composition of test subjects; those components that should not be decided by the standard (i.e. those aspects that should be left to the discretion of manufacturers or test operators) are to be included in the "black box" of the cells/stack assembly, and the standard should only cover the interface between these components and the measurement instrument system. This approach makes it possible for the standard to cover not only the cells but also the stacks.

Finally, after deciding to introduce the concept of uncertainty in order to ensure the reliability of measurement results, we needed to consider how to incorporate it into the standard and how to approach the evaluation equation. While a general equation for uncertainty is included in the Guide to the Expression of Uncertainty in Measurement (GUM), ${ }^{[7]}$ we believed it was not appropriate to adopt this directly as the equation for evaluating the uncertainty of the results of the SOFC performance tests. When a general equation is used for a specific application, many aspects are left to the discretion of users. In addition, there was concern that applying the general equation as is would leave too much work to the reviewer of the results, making the standard not very useful (and hence not usable). Thus we believed it was necessary to make the uncertainty equation for the standard as simple as possible, and clearly define and unify the method of using the equation in detail. The following is the approach we took to incorporate the uncertainty equation into the standard.

\section{Uncertainty of SOFC performance testing}

\subsection{Approaches to uncertainty evaluation}

Because the performance evaluation of SOFC is dependent on a wide range of parameters set for the measurement, calculating the uncertainty of the measurement results is not an easy process. Hence we investigated the approaches to uncertainty evaluation adopted in existing international standards related to fuel cells as well as in those standards currently under preparation.

The following are examples of approaches to uncertainty evaluation adopted in the international standards on fuel cells. It is clear from the issued years of the standards that, as of 2007 , there were only a very limited number of standards proposing to incorporate uncertainty evaluation into the performance evaluations of fuel cells.

(1) In "Stationary fuel cell power systems - Performance test methods," the Committee Draft for Voting (CDV) circulated in 2010 for IEC $62282-3-200,{ }^{[8]}$ uncertainty consists of and is evaluated in two categories: systematic uncertainty, which derives from factors such as the accuracy of measurement instruments and calibration errors; and random uncertainty, which derives from data variations. The CDV provides an example of how to combine and evaluate these two in one of the Annexes (including a table of computation results), but specific procedures are to be determined by consulting the GUM. The CDV's approach to uncertainty is roughly identical to that of the Performance Test Code for Fuel Cell Power System Performance published by the American Society of Mechanical Engineers (ASME)(ASME PTC 50$\left.2002^{[9]}\right)$, and in both cases the test is to be conducted in a steady state.

Uncertainty is calculated only for the measured efficiency of the system, and the sensitivity coefficients of component gases can be theoretically obtained by calculations. The performance evaluation of the SOFC system as a whole does not require setting the temperatures of the cells or the stack; thus there are fewer input quantities for the uncertainty evaluation of the system than for the uncertainty evaluation of a cell or stack. Only the uncertainties of thermal input and power output, which are dependent on factors such as fuel composition and flow rate, need to be considered.

(2) At the end of 2009, the above-mentioned FCTESQA submitted to IEC a Draft for Comment (DC) on the testing method of the current-voltage (I-V) characteristics of Polymer Electrolyte Fuel Cells (PEFC) (An unofficial IEC document; not included in the reference list for the present document). This testing method defines the allowable range 
for "measurement uncertainty." However, the document fails to draw a clear distinction between the variation of measurements and the uncertainty of measurements; for example, it defines "steady state" as the state in which the variation falls within a given range of measurement uncertainty. The document defines "measurement uncertainty" using a general equation that addresses the correlation between input parameters but does not provide any specific method for calculating uncertainty.

(3) The TS on "Single Cell Testing Methods for PEFC," which was published in $2010,{ }^{[10]}$ was still a Committee Draft (CD) when we were preparing the draft standard. The CD defined the maximum allowable variation of input quantities and the maximum uncertainty of testing equipment. The final version of the TS recommends that measurement uncertainty be included in the test report, as it is shown in the template provided in one of the Annexes. But again, the document points to the GUM as a guide for specific procedures. ${ }^{[7]}$

Based on the circumstances above, we established the following guiding principles on uncertainty evaluation in the proposed international standard for SOFC performance tests:

(a) Use the GUM as the guide for uncertainty evaluation and describe both the evaluation equation and the specific procedures for calculating uncertainty.

Uncertainty is obtained by combining the results of a Type A evaluation using statistical methods and a Type B evaluation using any other methods. We propose this approach because it would be difficult to derive the actual steps for evaluating uncertainty from the general uncertainty equation alone; leaving this task to the reviewer would result in a complete lack of consistency in the actual method used.

(b) Define the maximum variation of input quantities and the allowable uncertainty of measuring instruments, and perform all measurements in a stable state where input quantities stay within the allowable range.

This has the effect of setting approximate allowable values for both Type A and Type B uncertainty evaluations. Moreover, conducting measurements in a stable state eliminates the need to consider any correlation between input quantities when uncertainty is evaluated.

(c) Do not impose an unreasonable amount of work on the reviewer.

The purpose of the standard is to establish performance test methods for commercial purposes, not to obtain an accurate value of uncertainty. We believe that the goal of uncertainty evaluation would be achieved if the evaluation can show the level of accuracy at which a test operator has conducted the test and produced the results for submission; the test operator should not be expected to deviate substantially from the daily test procedures just to achieve this goal.

Based on these principles, we removed those aspects of the general equation of uncertainty evaluation that are believed to have little impact on uncertainty. We also provided a description of the specific procedures involved in uncertainty evaluation, so that the test operator would be able to easily conduct the evaluation.

\subsection{Description of uncertainty evaluation in the draft standard}

With the above circumstances taken into account, we included the following details concerning uncertainty evaluation in the draft standard:

The performance tests incorporated in the draft standard include the rated power test, I-V characteristic test, the effective fuel utilization dependency test, the long-term durability test, the internal impedance test and so on. Because uncertainty evaluations of some of these tests were likely to be very difficult or troublesome, our proposed draft standard only mandated that the uncertainty evaluation be conducted on the results of the rated power tests. Here, the rated power test was defined as the test in which either the current or the voltage is measured while the other is kept at a certain level: it is a single-point test in which all other control parameters are kept constant. An explanation is given below using an example where the voltage is measured while the current is kept constant - the more commonly used of the two methods.

Based on the guiding principles above, the draft standard established the maximum allowable variations of input quantities such as the current and the gas flow rate that were applicable to all the tests stipulated in the standard (Table 1). In an actual measurement, each test operator is to set a maximum allowable variation within this defined range, so that he/ she would be able to obtain the target uncertainty value of a particular measurand (a quantity subject to measurement). This in effect establishes the allowable range of uncertainty arising from random error.

In addition, "stable state" was defined as the state in which the system is stable enough for any input quantity to fall within the tolerance range set by the test operator and the measurement result to meet the target uncertainty level. All measurements were to occur after the test sample was confirmed to have attained the stable state. This would prevent the measurement from being conducted while the system is in a transient response arising from a sudden change in a condition or in various drift states. Consequently, measurement variations would be limited to those due to random noise or the uncontrollable minute variation of 
Table 1. Range of allowable variations and instrument uncertainty set by the draft standard and the feasibility of uncertainty evaluation of each input quantity

\begin{tabular}{|c|c|c|c|c|}
\hline input parameter & tolerable range of variation & instrument uncertainty & sensitivity coefficient & action to unceratinty evaluation \\
\hline voltage & $\begin{array}{l} \pm 1 \% \text { of set value (in case of voltage } \\
\text { control) }\end{array}$ & $\pm 0.5 \%$ of OCV & experimentally decided & incorporated \\
\hline current & $\begin{array}{l} \pm 1 \% \text { of rated current (in case of } \\
\text { current control) }\end{array}$ & $\pm 1 \%$ of rated current & experimentally decided & incorporated \\
\hline unit temperature & $\pm 1 \%\left({ }^{\circ} \mathrm{C}\right)$ of set temperature & $\pm 1 \%\left({ }^{\circ} \mathrm{C}\right)$ of rated temperature & $\begin{array}{l}\text { experimental (rated } \\
\text { temperature } \pm 50^{\circ} \mathrm{C} \text { ) }\end{array}$ & incorporated \\
\hline fuel flow rate & $\pm 1 \%$ of rated value & $\pm 1 \%$ of reading & $\begin{array}{l}\text { experimental (rated } \\
\text { flow rate } \pm 10 \sim 20 \%)\end{array}$ & incorporated \\
\hline oxidant flow rate & $\pm 1 \%$ of rated value & $\pm 1 \%$ of reading & $\begin{array}{l}\text { experimental (rated } \\
\text { flow rate } \pm 10 \sim 20 \%)\end{array}$ & incorporated \\
\hline fuel composition & $\begin{array}{l}\mathrm{H}_{2}, \mathrm{H}_{2} \mathrm{O}, \mathrm{N}_{2}: \pm 1 \text { mole\%, } \\
\mathrm{CO}, \mathrm{CO}_{2}, \mathrm{CH}_{4}: \pm 0.25 \text { mole\% }\end{array}$ & $\begin{array}{l}\mathrm{H}_{2}, \mathrm{H}_{2} \mathrm{O}, \mathrm{N}_{2}: \pm 2 \text { mole\%、 } \\
\mathrm{CO}, \mathrm{CO}_{2}, \mathrm{CH}_{4}: \pm 1 \text { mole\% }\end{array}$ & $\begin{array}{l}\text { depends on the method } \\
\text { of mixture supply (cannot } \\
\text { change indivisually) }\end{array}$ & \begin{tabular}{|l|} 
partially achieved \\
(e.g. presentation of the \\
composition table published \\
by gas manufacturer)
\end{tabular} \\
\hline oxidant composition & $\mathrm{O}_{2}: \pm 0.3$ mole\% ( $\mathrm{N}_{2}:$ balance) & $\mathrm{O}_{2}: \pm 0.3$ mole\% ( $\mathrm{N}_{2}:$ balance $)$ & $\begin{array}{l}\text { depends on the method } \\
\text { of mixture supply (cannot } \\
\text { change indivisually) }\end{array}$ & $\begin{array}{l}\text { partially achieved } \\
\text { (e.g. presentation of the } \\
\text { composition table published } \\
\text { by gas manufacturer) }\end{array}$ \\
\hline fuel temperature & $\begin{array}{l}\text { not prescribed particularly with the } \\
\text { condition that it does not attect } \\
\text { the performance }\end{array}$ & $\pm 1 \%$ of reading & $n / a$ & $\begin{array}{l}\text { not incorporated } \\
\text { (compromized with the } \\
\text { prescription that the test } \\
\text { should be conducted under } \\
\text { the condiiton that it does } \\
\text { not affect the performance) } \\
\end{array}$ \\
\hline oxidant temperature & $\begin{array}{l}\text { not prescribed particularly with the } \\
\text { condition that it does not attect } \\
\text { the performance }\end{array}$ & $\pm 1 \%$ of reading & $n / a$ & $\begin{array}{l}\text { not incorporated } \\
\text { (compromized with the } \\
\text { prescription that the test } \\
\text { should be conducted under } \\
\text { the condiiton that it does not } \\
\text { affect the performance) }\end{array}$ \\
\hline fuel pressure & $\pm 3 \mathrm{kPa}$ (atmospheric pressure operation) & $\pm 1 \%$ of reading & $n / a$ & not incorporated \\
\hline oxidant pressure & $\pm 3 \mathrm{kPa}$ (atmospheric pressure operation) & $\pm 1 \%$ of reading & $n / a$ & not incorporated \\
\hline atmospheric pressure & \multicolumn{2}{|c|}{$\begin{array}{l}\text { Not to be included in uncertainty evaluation, because it is not possible to change ambient } \\
\text { pressure with common test equipment. It was alternatively decided to report atmospheric } \\
\text { pressure. It may become problematic if atmospheric pressure differs much from } 1 \mathrm{~atm} \text {. } \\
\text { Normally it was confirmed by experiment that this effect on the performance is small. }\end{array}$} & $n / a$ & not incorporated \\
\hline temperature distribution & \multicolumn{2}{|c|}{$\begin{array}{l}\text { If the object has more than one temperature measurement points as is always the case } \\
\text { with large cells or stacks, it was decided that manufacture has to provide the tolerance } \\
\text { range of temperature distribution and the measurement has to be conducted within the } \\
\text { range. It was also decided that the temperature distribution should not be included in the } \\
\text { uncertainty evaluation. It was experimentally confirmed that the temperature distribution } \\
\text { could become negligible using } 100 \mathrm{~cm}^{2} \text { or such a level cells. }\end{array}$} & $n / a$ & not incorporated \\
\hline
\end{tabular}

input quantities, thereby minimizing the need to take into account any possible correlation between input quantities for uncertainty analysis.

The draft standard additionally defined the maximum allowable uncertainties of measurement instruments (i.e. uncertainty due to systematic error) (Table 1). This was specifically intended for the uncertainty of the instruments at the time of calibration. However, the draft standard also allowed a simplified Type B evaluation that assumes a uniform distribution, using catalog values such as the degree of accuracy of the instruments, on the condition that the instruments have been calibrated.

\section{Uncertainty of measurement of SOFC properties}

\subsection{Selection of factors affecting uncertainty through experimental verification}

The properties of SOFC depend on various factors such as cell temperature, fuel flow rate, air flow rate, operating pressure, and temperature distribution. It follows that the uncertainty of the control and measurement of these input quantities would inevitably have an effect on the uncertainty of the measurand. We decided to investigate how these input quantities would impact the uncertainty of the measurand, and, based on the results, grouped them into those that should be incorporated into uncertainty evaluation and those that should not.

As an example, figure 2(a) shows the pressure dependence of the voltage of an SOFC single cell that was measured while the atmospheric pressure was varied. The measurement was conducted in three different conditions: open circuit voltage (current: $0 \mathrm{~A}$ ); the fuel utilization rate at $50 \%$ (current: $24.4 \mathrm{~A}$ ); and the fuel utilization rate at $70 \%$ (current: $34.1 \mathrm{~A}$ ). The slopes of the plots represent the impact of the atmospheric pressure on the uncertainty of voltage measurements when the current and gas flow rate are kept constant and the pressure deviates from the set value.

The pressure dependence of the cell voltage obtained from the data shown in the graphs is approximately $0.3 \mu \mathrm{V} / \mathrm{Pa}$ at around 1 atmospheric pressure, demonstrating that if the measurement is made within the normal range of atmosphere, the impact that the atmospheric pressure variation has on measurand $V$ remains small. Incidentally, in our standard, the uncertainty of the measurand is to be kept at approximately $1 \%$ or below as a rough target.

SOFC varies not only by geometry and size, but also by the 
type of support used. Figure 2(a) above represents the test results of an electrolyte-supported cell. This type of cell is characterized by relatively thin electrode films on both sides of the electrolyte, making it less affected by diffusion of reaction species and reaction products in the porous electrodes.

In contrast, anode-supported and cathode-supported SOFC cells have a thicker porous medium and are therefore more susceptible to the effects of gas diffusion, raising the possibility that the operating-pressure dependence of the voltage of these types of cells would be substantively different from that of the electrolytesupported cell mentioned above.

Figure 2(b) shows the pressure dependence of the cell voltage measured in an anode-supported SOFC single cell. While the level of dependence observed on the lower pressure region is significantly different from what is observed above, the pressure dependence of the cell voltage at 1 atmospheric

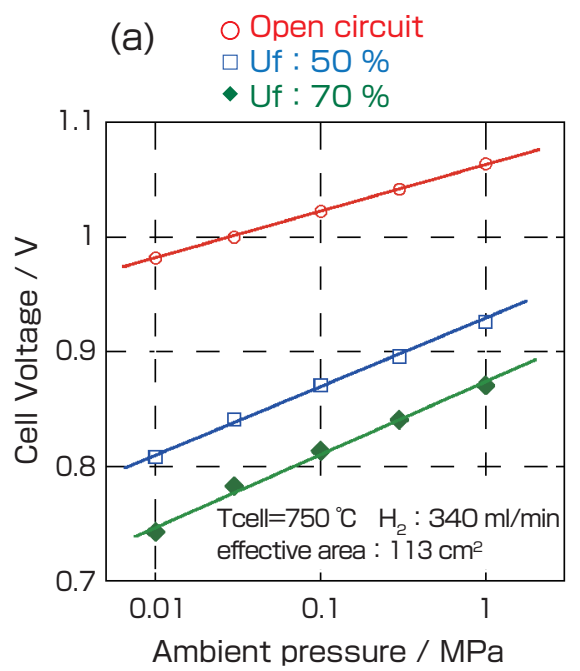

pressure is about 0.2 to $0.5 \mu \mathrm{V} / \mathrm{Pa}$, confirming its low impact on uncertainty for these types of cells as well.

In contrast, the temperature distribution of SOFC is a very troublesome issue as far as uncertainty is concerned. In theory, the performance of SOFC at a certain temperature can be obtained simply by uniformly maintaining that particular temperature all over the object and conducting measurements. But in practice, taking measurements in such a condition is not always possible. Moreover, based on the actual usage of SOFC, it is arguable that a temperature distribution should be the norm.

Therefore, for the purpose of this study we took measurements of the temperature distribution of a SOFC single cell, an example of which is shown in Fig. 3. In general, the temperature distribution varies depending on the setup in the electric furnace used and the method of temperature control

Fig. 2 Pressure dependence of the cell voltage at different fuel utilization rates

(a) Electrolyte-supported cell; (b) Anode-supported cell
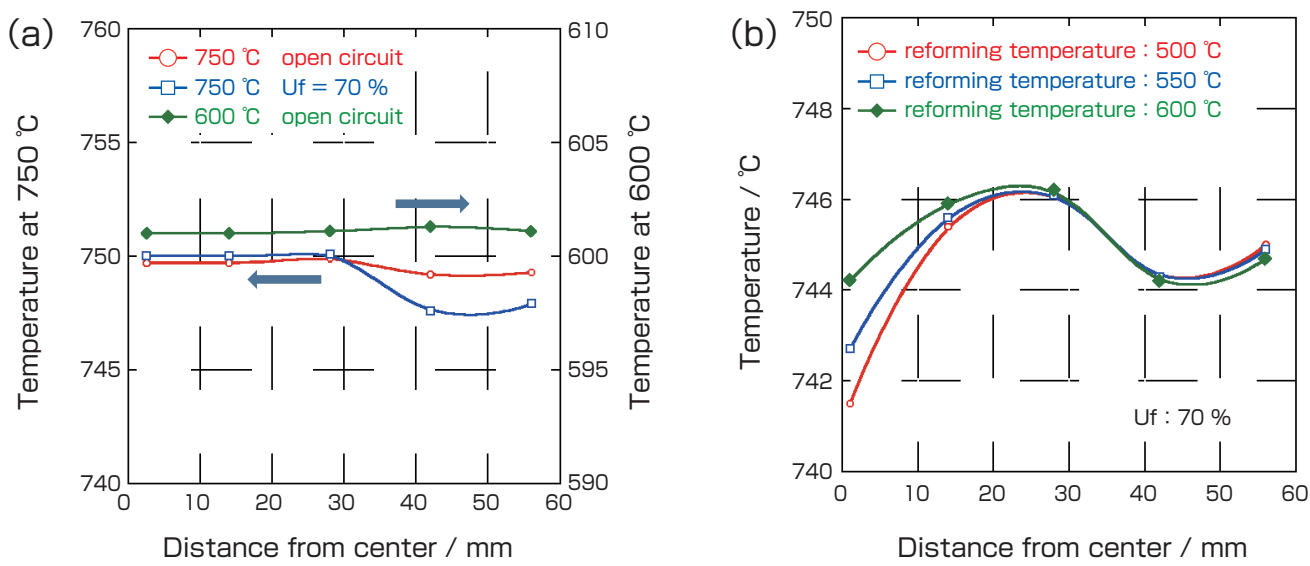

Fig. 3 Examples of temperature distribution measurement of a single cell Measurement by $0.25 \phi$ sheath thermocouple (Okazaki Super Couple 1000H).

(a) Electrolyte-supported cell (Active electrode area: $113 \mathrm{~cm}^{2}$. Fuel: pure hydrogen)

(b) Anode-supported cell (Active electrode area: $113 \mathrm{~cm}^{2}$. Fuel: partially-reformed methane) 
used to keep the temperature high. In our experiment, we set up the SOFC cell in the laboratory system we normally work on and employed the single-point control method for temperature control.

Figure 3(a) shows the temperature distribution of an electrolyte-supported cell-a type of cell of which internal reforming characteristic is not expected to be sufficient enough-when hydrogen was introduced as fuel. The hydrogen gas was supplied from the center of a discplate cell and then was circulated to the periphery. The graph demonstrates that, regardless of the load level, the temperature distribution remained within approximately $\pm 2{ }^{\circ} \mathrm{C}$ of the average cell temperature. Judging from the allowable variation of approximately $\pm 1 \%$ of the set value endorsed by the proposed draft standard, we believed this to be a sufficiently acceptable level.

In contrast, figure 3(b) shows the temperature distribution of an anode-supported cell when partially-reformed methane was used as fuel. This type of SOFC, unlike the electrolyte-supported cell, is expected to have sufficient internal reforming characteristic, which is one of the benefits of SOFC. From the graph it is evident that a decrease in the temperature at the inlet area occurred due to the endothermic reaction from the internal reforming of methane. While the temperature distribution varied according to the load level, it nevertheless remained within about $\pm 3{ }^{\circ} \mathrm{C}$ of the average temperature. If we could assume this temperature distribution as a local temperature variation within the cell, we judged that this degree of variation sufficiently falls within the allowable range even when internal reforming occurs. (Actual evaluation of the impact of temperature distribution is very difficult because local impedance changes as a result of temperature distribution, resulting in a change in current distribution.)

As shown above, it was verified through experiments that atmospheric pressure and temperature distribution have little impact on uncertainty, and hence it was decided that they were not to be incorporated into the equation for uncertainty evaluation. In reality their impact on uncertainty is not small enough to be completely ignored, and they should ideally be included in the equation. However, it is not realistic to expect cell manufacturers to make measurements of such parameters as pressure dependence and temperature distribution for all types of cells they produce. In fact, very few studies have been published on the measurements of pressure dependence or temperature distribution such as those conducted for this paper. Moreover, even if temperature distribution is measured, it would be very difficult to estimate its impact on uncertainty. For this reason, it was fortunate, in the end, that the impact of these factors on uncertainty was small and that it was possible to achieve the goal of uncertainty evaluation even when these factors were omitted from the uncertainty evaluation equation.
In addition, the draft standard provides that if there are multiple points of temperature measurement in a test unit, the manufacturer must determine the allowable range of temperature distribution in advance and conduct the measurements within that allowable range. In other words, as long as the temperature is measured within the range, it is not necessary to take into consideration the uncertainty resulting from temperature distribution.

\subsection{Uncertainty equation used in the draft standard}

Given the circumstances described above, we proposed the following equation in the draft standard for evaluating uncertainty when the voltage of SOFC, $V$, is measured while input quantity, $X_{j}$, is being controlled.

$u(V)^{2}=u_{I}(V)^{2}+u_{F}(V)^{2}+\sum_{j}\left(\left(\frac{\partial V}{\partial X_{j}}\right)^{2}\left(u_{I}\left(X_{j}\right)^{2}+u_{F}\left(X_{j}\right)^{2}\right)\right)$

where $u(X)$ is the standard uncertainty of $X$; subscript $I$ is the uncertainty of measurement instruments; subscript $F$ is the uncertainty due to variations; and

$\frac{\partial V}{\partial X_{j}}$

is the sensitivity coefficient of measurand $V$ to input quantity $X_{j}$. The last was to be determined through a laboratory experiment. In addition, it was decided that the sensitivity coefficient should be used to correct the value of the measurand multiplying the difference between the average value and the set value of an input quantity. Table 1 shows the input quantities to be evaluated by the uncertainty evaluation equation based on the circumstances and the experimental results shown above.

In one of the Annexes to the draft standard, we showed the method of calculating the instrument uncertainty of temperature, current, flow rate, and voltage, as well as the method of calculating the uncertainty of the measurand by combining the instrument uncertainty and the uncertainty resulting from measurement variations. We believe that this approach ensures that the evaluation of uncertainty is conducted in a consistent manner without leaving the equation open to interpretation.

\subsection{Relationship between measurand and input quantity (measurement of sensitivity coefficients)}

We proposed that the sensitivity coefficients used in the uncertainty equation are to be obtained by actual measurements. Because it was decided that the evaluation of uncertainty was to be made only at rated values, as mentioned above, the measurements of sensitivity coefficients were to be made by measuring the voltage while varying the 
Table 2. An example of an uncertainty budget table on the current-regulated rated power test using an SOFC single cell

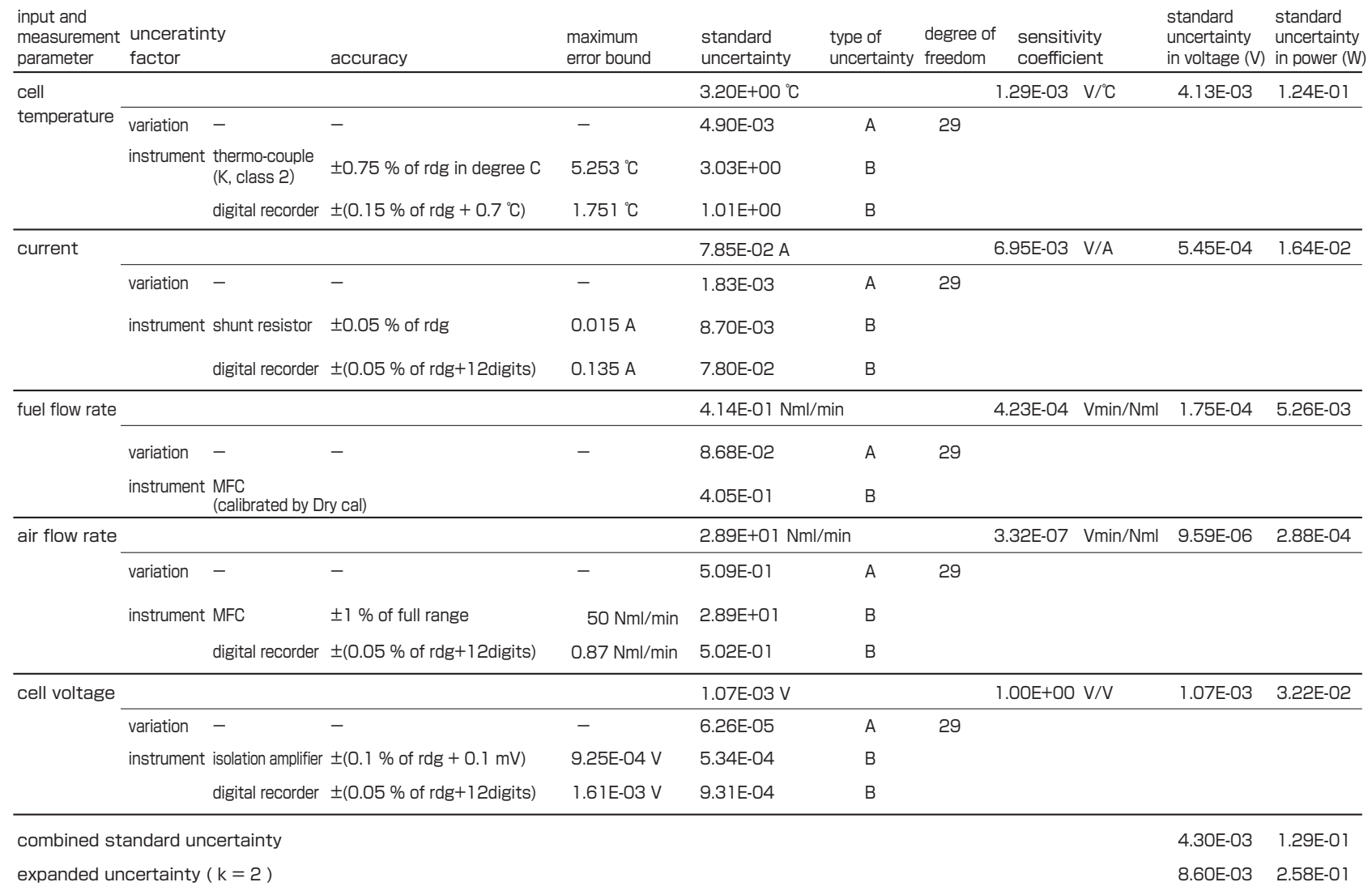

input quantities around the rated values.

As an example, figure 4 shows the measurement data taken to calculate the sensitivity coefficient of the voltage to the unit temperature. When the rated value is $750{ }^{\circ} \mathrm{C}$ and the fuel utilization rate is $70 \%$, the slope obtained at that particular point in the plot is the sensitivity coefficient. Generally speaking concerning the variation in the experiment for obtaining sensitivity coefficients, SOFC manufacturers make the measurements by varying input quantities, such

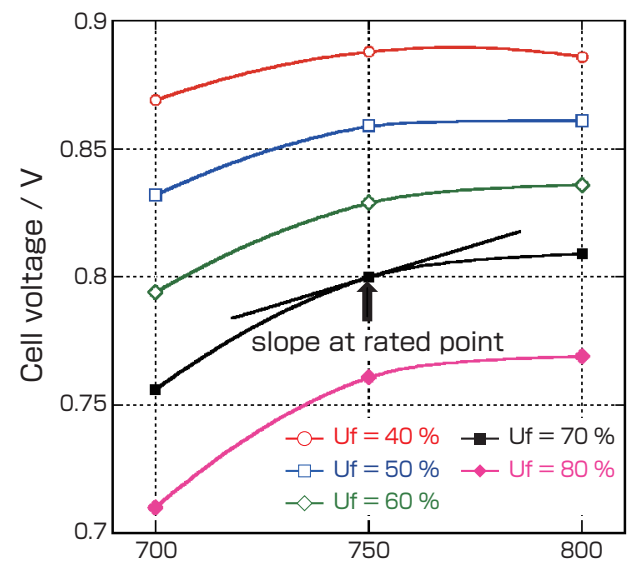

Cell temperature $/{ }^{\circ} \mathrm{C}$

Fig. 4 An experiment to calculate the sensitivity coefficient of the cell voltage to the temperature

The variation range of the input quantity was set at about $\pm 50^{\circ} \mathrm{C}$. as temperature and gas flow rate, around the rated values. For unit temperature, a variation of $50{ }^{\circ} \mathrm{C}$ is normally used. Thus, we recommended in the draft standard that the range of the unit temperature for calculating the sensitivity coefficient be approximately $\pm 50^{\circ} \mathrm{C}$. The data in figure 4 can be obtained by measuring the I-V characteristics at a rated temperature and at $\pm 50{ }^{\circ} \mathrm{C}$. We took this approach so that this measurement of the sensitivity coefficient would not pose an undue burden on the manufacturers.

In some cases, it is simply not possible to measure the sensitivity coefficient, and thus it is not possible to evaluate uncertainty. Table 1 shows how to obtain the sensitivity coefficient for each input quantity in the SOFC test and whether it is possible to evaluate uncertainty. However, it may not be possible to evaluate uncertainty originating from fuel and oxidizing gas compositions. When gas is supplied using a mixture gas cylinder, for example, it is virtually impossible to independently change the concentration of one component gas of the gas mixture to measure its sensitivity coefficient, thus making it impossible to evaluate the impact of the uncertainty of a component gas on the voltage.

\section{An example of uncertainty analysis for the SOFC performance test}

Table 2 shows an example of uncertainty analysis (uncertainty budget table) conducted on the results of the 
rated power test on a $100 \mathrm{~cm}^{2}$ planar SOFC single cell. For the test we used the measurement and control instruments that we normally used for performance tests. When there is a large variation in the measurement values, the level of uncertainty may be reduced by making repeated runs of measurements. However, as long as the system is in a stable state, a single run of about 30 measurements (1 measurement/ second) would show that the impact of the variation of measurement values on uncertainty is small.

The objective of the rated power test is to produce power output, which is obtained by multiplying the current, the input quantity, and the voltage, the measurand. Thus the column on the right end of Table 2 shows the uncertainty converted to power. A comparison of the uncertainty values demonstrates that the majority of uncertainty derives from the temperature measurement of the cell. It is also clear from the breakdown of this source of uncertainty that the thermocouple used in the test accounts for a significant portion of that uncertainty.

One of the benefits of uncertainty analysis is that by producing a data set like Table 2, one can easily see which measurement needs to be improved in order to reduce the level of uncertainty in the measurand. By changing the thermocouple used for the measurement from a type-k thermocouple (class 2), which was used for this measurement, to a class-1 thermocouple, it is possible to reduce the standard uncertainty of power output measurement from $0.13 \mathrm{~W}(0.52 \%)$ to $0.08 \mathrm{~W}(0.33 \%)$.

From the above, we believe that the impact of the uncertainty on the variation of the measured values would remain small, so long as the measurement is made by carefully making sure that the system is in a stable state. It follows, then, that it is possible to derive a rough estimate of the uncertainty of test results solely from the uncertainty of the measuring instruments used in that test.

Thus, when the uncertainty of the above-mentioned cell was calculated with the assumption that the measurement instruments used for the calculation had the maximum allowable range of the instrument uncertainty set by the draft standard, the relative expanded uncertainty was estimated to be $1.4 \%$. Since the draft standard prescribes that an instrument falling within the allowable range of uncertainty be used, it follows that the test operator would be able to obtain a measurement result with the relative expanded uncertainty of approximately $1.4 \%$ at the maximum. However, it should be noted that this value may change significantly from one test unit to another, such as when the unit has a completely different sensitivity coefficient or when the rated condition is characterized by a high fuel utilization rate.

\section{Summary}

The maximum variations of input quantities and the uncertainty values of the instruments established in the draft standard were based on a set of working values that were initially prepared by our group and were subsequently discussed and adopted by the committee as the final values acceptable to all manufacturers. In conclusion, our study demonstrated that by conducting a test in accordance with the draft standard, it is possible to obtain a measurement with a relative uncertainty of approximately $1.4 \%$ at the maximum. We believe that the values proposed in the draft standard were reasonable for the commercial transactions of SOFC.

In the end, however, the uncertainty analysis and its equation for the rated power test that we proposed were omitted from the final version of the draft standard by the national committee responsible for preparing the New Work Item Proposal (NP) for submission to IEC. As a result, only the maximum allowable variation of the input quantities (control parameters) and the instrument uncertainty remained in the NP. Nevertheless, it was still fortunate that we were able to verify the maximum uncertainty value as described above.

The main reason that the uncertainty analysis was removed from the draft standard is that many manufacturers are still not familiar with the concept of uncertainty and they focused above all on the troublesome nature of the uncertainty analysis. In proposing the equation for uncertainty evaluation, we did our best to present an equation (method) that would minimize the burden on the test operator, but we failed to provide sufficient evidence on the merit of conducting uncertainty evaluation.

The concept of uncertainty ensures the reliability of data across borders through the traceability system. It is recommended by many international standard organizations and is likely to be incorporated into an increasing number of international standards in the decades to come. At the same time, however, it may take some time to convince the manufacturers in this field that the potential benefit of uncertainty evaluation makes it worthwhile to incorporate it in their testing procedures if they aim to produce quality products.

This draft standard is currently being reviewed by an international Working Group (WG), and it may see an introduction of the uncertainty evaluation any time as a result of a proposal by another country. In addition, as far as our national committee is concerned, it appears that the concept of uncertainty is gradually gaining in prevalence among the committee members as a result of our presentation and the discussions held on the topic. Therefore, given that uncertainty evaluation may be proposed at any time, we believe that our work has helped to lay the groundwork for determining whether or not it should be adopted.

While we, the authors, are not experts on uncertainty, there 
seems to be a common saying among the specialists in the field that "the biggest uncertainty lies in those factors that have not been considered." In our evaluation of uncertainty for the draft standard, the following may fall under that category:

(1) Change in performance due to temperature distribution (as suggested above);

(2) Operator-to-operator variability;

(3) Sample variability;

(4) Drift due to time-dependent change.

It follows therefore that we have not been able to escape the curse of the above-mentioned proverb, either. Some of these factors were intentionally omitted based on our guiding principles on uncertainty evaluation. The concept of drift due to time-dependent degradation is crucial when discussing the durability of SOFC, and we are currently in the midst of discussions regarding the testing methods for the durability of SOFC. ${ }^{[11]}$

Thus, we have discussed the approach we have selected for international standardization that is a must for a new technology to become globally commercialized and accepted. We would consider it a work well done if it can in any way serve as a guide for our colleagues involved in the development of technology, and at the same time invite you to submit any feedback or criticisms of uncertainty evaluation.

\section{Acknowledgement}

This study was made possible by the Research and Development Project on Standardization and Certification and the Joint Research and Development Project on International Standardization funded by METI. We would like to thank the members of the Committee for the Research and Development of the Standardization of SOFC Unit Cell Assembly Testing Methods as well as all other firms and organizations involved for their cooperation in the preparation of the draft standard.

\section{References}

[1] http://fctesqa.jrc.ec.europa.eu/

[2] JIS TS C 0054, Testing method of power generation efficiency for solid oxide fuel cell power systems fueled with gas in which methane is main component(2010) (in Japanese).

[3] T. Kato et al.: View and Development of Solid Oxide Fuel Cells, ed. by K. Eguchi, CMC Books, 179-190 (2010) (in Japanese).

[4] New Energy and Industrial Technology Development (NEDO): "Research on the Technology for the Evaluation of System Efficiency Measurement," System Performance Evaluation Technology Development, SOFC Fuel Cell System Performance Technology Evaluation Technology,
SOFC Fuel Cell System Technology Development, NEDO Activity Report 2007, (2008) (in Japanese).

[5] Y. Tanaka, A. Momma, A. Negishi, K. Kato, K. Takano, K. Nozaki and T. Kato: Progress towards realizing distributed power generation with highly efficient SOFC systems, Synthesiology, 6(1), 12-23 (2013) (in Japanese).

[6] Y. Tanaka, A. Momma, K. Kato, A. Negishi, K. Takano, K. Nozaki and T. Kato: Development of electrical efficiency measurement techniques for $10 \mathrm{~kW}$-class SOFC system: Part II. Uncertainty estimation, Energy Conversion and Management, 50 (3), 467-478 (2009).

[7] ISO/IEC Guide. Guide to the Expression of Uncertainty in Measurement (GUM), International Organization for Standardization, 98 (1995).

[8] IEC 62282-3-200 Ed.1 (CDV). Fuel cell technologies - Part 3-200: Stationary fuel cell power systems - Performance test methods.

[9] ASME PTC 50-2002. Fuel Cell Power Systems Performance - Performance Test Codes.

[10] IEC/TS 62282-7-1. Fuel cell technologies - Part 7-1: Single cell test methods for polymer electrolyte fuel cell (PEFC).

[11] NEDO: "Standardization of SOFC Single Cell/Stack Durability Testing Method," Project for Strategic Promotion of International Standardization/Leading Research on Standardization, NEDO Activity Report 2010 (2011) (in Japanese).

\section{Authors}

\section{Akihiko Momma}

Completed the doctoral program of the Metallurgical Engineering Department at Tokyo Institute of Technology in 1985. Worked at SRI International as a guest researcher and subsequently joined the Electrotechnical Laboratory Japan (the predecessor of the National Institute of Advanced Industrial Science and Technology (AIST)), where he engaged

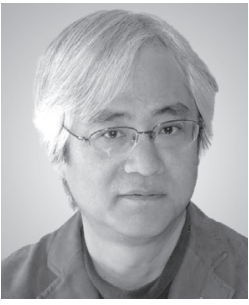
in the research and development of SOFC. Currently senior research scientist of the Fuel Cell System Group of AIST's Energy Technology Research Institute and specializes in electrochemical measurements and evaluations. In preparing for this paper, he was responsible for managing the committee work, conducting various electrochemical measurements, evaluating the uncertainty equation, and writing and editing.

\section{Kiyonami TAKANO}

Graduated from the Department of Electrical and Electronic Engineering of the Faculty of Engineering of the University of Tokushima in 1966. Joined the Electrotechnical Laboratory of the Agency of Industrial Science and Technology of the Ministry of International Trade and Industry (the predecessor of METI). After engaging in the research of the simulation technology of lithium secondary battery from 1991, began working on the research for the power generation evaluation of SOFC in 2001. Currently guest researcher at the Fuel Cell System Group of the Energy Technology Research Institute. In this study, he was in charge of conducting pressure dependence tests for single cells, temperature distribution measurements, and uncertainty evaluation. 


\section{Yohei TANAKA}

Completed the doctoral program of the Department of Energy and Hydrocarbon Chemistry, Graduate School of Engineering of Kyoto University in 2005 and joined AIST in the same year. Currently senior research scientist at the Fuel Cell System Group of the Energy Technology Research Institute. His areas of specialization include catalyst

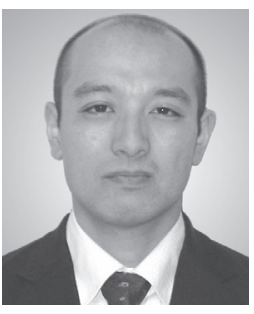
chemistry, fuel cell performance evaluation, and energy engineering. For this paper, he was responsible for preparing the gas supply methods and the uncertainty evaluation methods for the draft standard.

\section{Tohru KaTo}

Completed the graduate program at Tohoku University and earned a doctorate degree in engineering in 1991. In 1992, joined the Electrotechnical Laboratory Japan of the Agency of Industrial Science and Technology of MITI, where he conducted research on the technology for high temperature electrolysis. Currently serves as Industrial Science

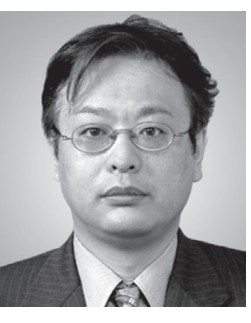
and Technology General Director for the Research and Development Division under the Industrial Science and Technology Policy and Environment Bureau of METI. For the preparation of this paper, he was responsible for the establishment and operation of the national committee, preparation and editing of the draft standard, the proposal for the concept of cell stack/assembly unit, and the oversight of the research project as a whole.

\section{Discussions with Reviewers}

\section{Justification of the parameters chosen for uncertainty evaluation \\ Question (Hiroshi Tateishi, AIST)}

In "3.2 Description of uncertainty evaluation in the draft standard," it is stated, "Because uncertainty evaluations of some of these tests were likely to be very difficult or troublesome, our proposed draft standard only mandated that the uncertainty evaluation be conducted on the results of the rated power tests." The reasoning for omitting the "difficult or troublesome" evaluations is not clear. If these omitted steps had a major impact on uncertainty, wouldn't the entire process lose its credibility?

\section{Answer (Akihiko Momma)}

What we meant by this is that we made uncertainty evaluation mandatory only for the results of the rated power test in the draft standard. For other test results, the users themselves were to judge the reliability of data from the information on measurement instruments, which must be included in the test report according to the draft standard. Therefore, it is not that the uncertainty of the rated power test depends on the results of those other tests that the draft standard did not make it mandatory to perform uncertainty evaluation, as you suggested. Uncertainty evaluation was in fact difficult for some tests other than the rated power test. For others, we actually did not know what to do, and decided not to require them. We judged that imposing an excessive burden on test operators for uncertainty evaluation would go against the view of the committee by being not consistent with its overall goal to make the standard as user friendly and accessible as possible.

\section{If uncertainty evaluation is not feasible Question (Hiroshi Tateishi)}

At the end of " 4.3 Relationship between measurand and input quantity (measurement of sensitivity coefficients)," it says, "When gas is supplied using a mixture gas cylinder, for example, it is virtually impossible to independently change the concentration of one component gas of the gas mixture to measure its sensitivity coefficient, thus making it impossible to evaluate the impact of the uncertainty of a component gas on the voltage." Wouldn't the fact that it is "impossible to evaluate" the impact of uncertainty present a problem?

\section{Answer (Akihiko Momma)}

In the draft standard, a number of scenarios were considered to establish the methods of supplying fuel gas. When a mixed gas cylinder is used to supply fuel, we judged that it was practically impossible to conduct uncertainty evaluation. In this case, users would determine the reliability of data by referring to the test conditions and gas composition analysis table, which the standard requires to be included in the test report. We had no choice but to resort to this difficult decision even though there is no doubt that it is problematic. 